\title{
Characterization of Wnt Genes in Argopecten Scallops and Their Involvement in Responses to Different Temperature Stresses in Bohai Red Scallops
}

\section{Caihui Wang}

Qingdao Agricultural University

\section{Min Chen}

Chinese Academy of Sciences

Bo Liu

Qingdao Agricultural University

Junhao Ning

Chinese Academy of Sciences

Xia Lu

Chinese Academy of Sciences

Jinsheng Zhang

Zhaoyuan Xiadian Agricultural Technology Promotion Station

Chunde Wang ( $\nabla$ chundewang2007@163.com )

Qingdao Agricultural University

\section{Research Article}

Keywords: Peruvian scallop, bay scallop, Bohai Red scallops, Wnt genes, Temperature change, qRT-PCR

Posted Date: August 27th, 2021

DOI: https://doi.org/10.21203/rs.3.rs-829136/v1

License: (c) (i) This work is licensed under a Creative Commons Attribution 4.0 International License. Read Full License 


\section{Abstract}

Background: Bohai Red, a new Argopecten scallop strain selected from the hybrids between the Peruvian scallop, Argopecten purpuratus and the bay scallop northern subspecies, A. irradians irradians, is now one of the most cultured scallop strains in northern China. As one of a series of studies focusing on adaptation of Bohai Red scallops to fluctuations in environmental factors, this study aimed to examine the expression profile of Wnt genes in response to different temperature stresses in Bohai Red.

Results: As Bohai Red scallops were originated from the hybrids between the Peruvian scallop and the bay scallop northern subspecies, we first identified all Wnt genes from the genomes of the Peruvian scallop and the bay scallop northern subspecies, as well as the bay scallop southern subspecies, $A$. $i$. concentricus. Twelve Wnt members were identified from the two subspecies of bay scallop, and $13 \mathrm{Wnt}$ genes were found in the genome of the Peruvian scallop. Protein structure analyses showed that most Wnt genes poses all 5 conserved motifs except Wnt 1, Wnt 2, Wnt 6 and Wnt 9 in the bay scallops and Wnt2 and Wnt9 in the Peruvian scallop. Unexpectedly, Wnt8 gene was present while Wnt3 was absent in both the bay scallops and the Peruvian scallop. Phylogenetic analysis revealed that Wnt3 may have disappeared in the early evolution of mollusks. The expression profile of Wnt genes in Bohai Red exposed to different temperatures were examined by qRT-PCR. The results showed that expression of Wnt genes responded differentially to temperature changes. The Wnt genes such as Wnt1, Wnt6, Wnt7, Wnt11 and WntA that responded slowly to low and high temperature stresses may be related to the maintenance of basic homeostasis. Other Wnt genes such as Wnt4, Wnt9, Wnt5 and Wnt2 that responded rapidly to low temperature may play an important role in organismal protection against low temperature stress. And yet some Wnt genes including Wnt10, Wnt16, and Wnt8 that responded quickly to high temperature stress may play key roles in response to organismal stress provoked by high temperature stress.

Conclusions: Wnt genes are well conserved in Argopecten scallops, as in other bivalves. Wnt genes may play important roles in adaptation of Bohai Red scallops to changing temperatures. The results in this study will provide new insights into the evolution and function of Wnt genes in bivalves and eventually benefit culture of Bohai Red scallops.

\section{Background}

The Wnt genes encode a class of secreted glycoprotein ligands with approximately 350-400 amino acids in length, including 23-24 conserved cysteines with one or more N-terminal glycosylation sites and highly conserved sequence regions in different species [1]. Signaling pathways invoked by Wnt molecules are involved in the regulation of diverse biological processes that play crucial roles in the development of living organisms, including differentiation of cell morphology, maintenance of homeostasis as well as embryonic axis formation, regeneration of tissues, and regulation of immune responses [2-3]. Phylogenetic studies have suggested that $13 \mathrm{Wnt}$ subfamilies may have existed in a common ancestor of cnidarians and bilaterian symmetrical animals, unique to metazoans but not yet found in unicellular eukaryotes and plants [4]. Interestingly, gene loss often occurs in the evolution of Wnt genes in bilateral 
animals [5], but significant Wnt gene expansion is found in mammals [6], implying that homologous Wnt genes may be involved in the process of selection and adaptation to environment. In molluscs, the number of Wnt genes was found to vary from 11-34, but varied between 11-13 in bivalves. Studies in Ruditapes philippinarum have suggested that Wnt gene expansions may play an important role in larval development and shell color pattern formation [7]. Studies in oysters suggest that Wnts may coordinate and participate in homeostasis and tissue morphogenesis, as well as in dealing with the challenging environment [8]. Twelve and 11 Wnt subfamilies have also been found in the Japanese scallop (Patinopecten yessoensis) and Zhikong scallop. However, no Wnt genes have been identified in Argopecten scallops up to now.

Bohai Red, a new Argopecten scallop strain selected from the hybrids between the Peruvian scallop, Argopecten purpuratus and the bay scallop northern subspecies, $A$. irradians irradians, is now one of the most cultured scallop strains in northern China. The bay scallops, including the northern subspecies, $A$. irradians irradians and the southern subspecies $A$. irradians concentricus that are native to the Atlantic coast of the United States, with a wide distribution from Cape Cod to New Jersey and North Carolina, were introduced from the United States to China in the 1980s and 1990s, respectively. They have developed rapidly into vast industries in northern and southern China mainly due to their fast growth, short culture period and wide temperature tolerance range. However, since both subspecies are small in adult size with relatively short life spans [9-11] and in addition, since long-term inbreeding since their original introduction had led to severe depression in genetic diversity, the bay scallop culture industry had suffered significant losses around the turning of the century. Peruvian scallop, also known as Chilean scallop, a medium-sized scallop naturally distributed along the Pacific coast of South America [12], was then introduced into China in 2007, in hope to replace the small-sized bay scallops [13]. Although they were successfully reproduced in the hatchery, most Peruvian scallops did not survive the high temperature (up to $28.6^{\circ} \mathrm{C}$ ) in the summer in Qingdao. To utilize the genetic resources in the Peruvian scallop and the bay scallop, hybrids were produced between them which exhibited great heterosis in growth [14]. As the resulted hybrids were mainly male sterile, to overcome the difficulty in seed production from these hybrids, three new hermaphroditic strain, Bohai Red [15], 'QN orange' [16] and 'QN-2' [17], were selected and soon became one of the most cultured scallop varieties in northern China. In order for better culture of these new strains, a series of studies were carried out on the biology of these new strains. Our aim of this study is to examine the expression profile of Wnt genes in the strain Bohai Red under different thermal stresses.

Global warming is becoming a global problem. Increased temperature greatly affected the marine ecosystem [18]. Temperature is a key variable in all biological systems, because it can directly affect all biological processes and physiological mechanisms such as metabolism and oxidative stress [19]. Oxidative stress is caused by an imbalance between the production of oxidants and their removal by antioxidants and antioxidant enzymes. The short-term increase of temperature will increase the oxidative stress of Antarctic vertebrates and invertebrates [20]. When exposed to an acutely increased temperature, 
Pagothenia borchgrevinki showed an increased antioxidant capacity, but showed significant oxidative damage to lipids when exposed to prolonged higher temperatures [21].

As Bohai Red scallops were originated from the hybrids between the bay scallop northern subspecies and the Peruvian scallop, whose genomes are recently published, we first performed genome-wide identification of the Wnt genes in the bay scallop northern subspecies and the Peruvian scallop, as well as the bay scallop southern subspecies, whose genome is also available recently. We then conducted an evolutionary analysis involving the newly identified Wnt genes in these Argopecten scallops. Finally, we analyzed the expression profiles of Wnt genes in Bohai Red scallops under different temperature stress conditions. This study may provide new basis for further understanding of the evolution of Wnt genes in bivalves and their possible roles in adaptation to thermal stress in scallops, which may eventually benefit Bohai Red culture industry.

\section{Materials And Methods}

\section{Identification of Wnt genes in Argopecten scallops}

Genomes of the bay scallops, including the northern subspecies (BioSample accessions: SAMN08322131) and southern subspecies (BioSample accessions: SAMN10600613), and Peruvian scallop (BioSample accessions: SAMN08022140) used in this study were published previously [22-23]. Wnt genes in the Argopecten scallops were retrieved from the genomes of these scallops using a local BLAST search with the Wnt genes from the Japanese scallop. The conservative domains of Wnt genes (PF00110) were obtained from Pfam database (http://pfam.xfam.org/) and homologous genes were searched using Hidden Markov Models (HMM). The results were combined and used to predict the molecular weight as well as the isoelectric point of the amino acid sequence of the Wnt gene using the ExPASY proteomics server (http://expasy.org/). The obtained Wnt protein sequences were submitted to MEME program (https://meme-suite.org/meme) to obtain EML files, and to predict motifs using Tbtools [24]. Gene structure prediction was performed using Tbtools (gene structure view). Multiple sequence alignment was performed using DNAMAN.

\section{Phylogenetic analysis}

A multiple sequence alignment was performed using Clustal W with the amino acid sequences of Wnt genes from the bay scallops and the Peruvian scallop. The aligned sequences were submitted to MEGA7.0 software [25-26] to construct the phylogenetic tree using neighbor joining method ( $N J)$ with specific parameters set at: Bootstrap $=1000$, Model $=$ P-distance, Gap $=$ Partial deletion, Site Coverage Cutoff $=50 \%$. The whole amino acid sequences of Wnt genes from Crassostrea_giga (Cgi), Crassostrea_virginica (Cvi), Octopus_bimaculoides (Obi), Lingula_anatina (Lan), Lottia_gigantea (Lgi), Helobdella_robusta (Hro), Amphimedon_queenslandica (Aqu), Caenorhabditis_elegans (Cel), Strongylocentrotus_purpuratus (Spu), Aplysia_californica (Aca), Danio_rerio (Dre), Drosophila_melanogaster(Dme), Mytilus_galloprovincialis (Mga), Echinococcus_multilocularis (Emu), 
Patinopecten_yessoensis (Pye), Argopecten_irradians_concentricus (Aic), Argopecten_irradians_irradians (Aii), Argopecten_purpuratus (Apu), Nematostella vectensis (Nve) were used.

\section{Expression profile of Wnt genes in Bohai Red scallops}

Bohai Red scallops were obtained from the hatchery of Yantai Spring-Sea AquaSeed Co., Ltd. located at Laizhou, Shandong Province. Scallops were adapted to laboratory conditions (salinity at 28.0 and temperature at $23^{\circ} \mathrm{C}$ ) for one week before the experiment. The scallops were fed three times a day with water changed twice each day to maintain a stable temperature. Scallops were then transferred from holding tanks at $23^{\circ} \mathrm{C}$ directly to experimental tanks set at $2^{\circ} \mathrm{C}, 6^{\circ} \mathrm{C}, 11^{\circ} \mathrm{C}, 28^{\circ} \mathrm{C}, 30^{\circ} \mathrm{C}$ and $32^{\circ} \mathrm{C}$. Thirty scallops were set for each temperature group. Water temperature in the tanks was maintained by Thermostatic controllers (Type CW1500, Guangdong Zhisheng Group Co., Ltd.). Three scallops were sampled at $2 \mathrm{~h}, 4 \mathrm{~h}, 6 \mathrm{~h}, 8 \mathrm{~h}, 10 \mathrm{~h}$ and $24 \mathrm{~h}$ and dissected to collect their hepatopancreas. The tissues at each time point were pooled together to form one sample. The samples were immediately put in liquid nitrogen and subsequently transferred to $-80^{\circ} \mathrm{C}$ for subsequent RNA extraction.

RNA was extracted with an RNA Extraction Kit (RNAprep pure Tissue kit, 50 perps). Primers designed based on Wnt genes identified in the bay scallop and the Peruvian scallops were used for qRT-PCR analysis (BIO-RAD CFX96), with EF-1a as an internal control gene. Single stranded cDNA was synthesized using a Reverse Transcription Kit (Hiscript III RT Supermix for qPCR + gDNA wipe, r323-01) and a Fluorometric Quantitation Kit (Chamq Universal SYBR qPCR Master Mix, q711-02). For qRT-PCR experiments, the reaction system was $10 \mu \mathrm{l}$, and the cycling program was set as: pre-denaturation at 95 ${ }^{\circ} \mathrm{C}$ for $30 \mathrm{~s}$; cycling parameters $95^{\circ} \mathrm{C}$ for $10 \mathrm{~s}$ and $60^{\circ} \mathrm{C}$ for $30 \mathrm{~s}$ were run for 39 cycles. All data were analyzed using the $2^{-} \triangle \Delta \mathrm{CT}$ method.

\section{Results}

\section{Identification and gene structure analyses of Wnt genes in the bay scallops and Peruvian scallop}

In total, 12 Wnt genes with 148-385 aa and molecular weight of 16.9-44.0 KD were identified from the whole-genome sequences in both the northern (Additional file 1) and southern subspecies of bay scallop (Table 1). No difference in gene sequence was found between Wnt genes in the northern and southern subspecies. So subsequently we analyzed only the Wnt genes of the bay scallop southern subspecies. In Peruvian scallop, 13 Wnt genes were identified with 153-385 aa and with molecular weight of 17.5-44.0 KD (Table 1) [8]. The results also showed that a signal peptide containing 17-46 aa was found in 7 Wnt genes in the bay scallops (Wnt4, Wnt5, WntA, Wnt7, Wnt8, Wnt11 and Wnt16) and in 10 Wnt genes in the Peruvian scallop (Wnt1, Wnt2, Wnt4, Wnt5, Wnt6, WntA, Wnt7, Wnt8, Wnt9 and Wnt11). 
Table 1

Sequence analyses of Wnt genes in the bay scallops (Aix = Aic, Aii) and the Peruvian scallop (Apu)

\begin{tabular}{|c|c|c|c|c|c|c|}
\hline Species & Group & $\begin{array}{l}\text { Signal peptide } \\
\text { initiation }\end{array}$ & Domain & $\begin{array}{l}\text { Size } \\
(\mathrm{aa})\end{array}$ & $\begin{array}{l}\text { Molecular } \\
\text { Weight(D) }\end{array}$ & $\begin{array}{l}\text { Isoelectric } \\
\text { point }\end{array}$ \\
\hline Aix & Wnt1 & & $56-321$ & 346 & 39016.88 & 9.73 \\
\hline Aix & Wnt2 & & $1-296$ & 315 & 35801.3 & 9.46 \\
\hline Aix & Wnt4 & $6-23$ & $51-355$ & 355 & 40050.34 & 9.42 \\
\hline Aix & Wnt5 & $12-33$ & $59-369$ & 369 & 41764.01 & 9.17 \\
\hline Aix & Wnt6 & & $1-147$ & 148 & 16767.41 & 8.58 \\
\hline Aix & WntA & $1-22$ & $60-360$ & 360 & 40784.96 & 9.32 \\
\hline Aix & Wnt7 & $1-47$ & $61-371$ & 371 & 42034.7 & 9.16 \\
\hline Aix & Wnt8 & $1-25$ & $58-353$ & 355 & 40425.67 & 9.65 \\
\hline Aix & Wnt9 & & $30-335$ & 335 & 38731.2 & 9.42 \\
\hline Aix & Wnt10 & & $83-385$ & 385 & 43956.37 & 9.4 \\
\hline Aix & Wnt11 & $1-25$ & $50-355$ & 355 & 39526.99 & 9.61 \\
\hline Aix & Wnt16 & $1-40$ & $52-359$ & 359 & 40712.8 & 9.29 \\
\hline Apu & Wnt1 & $1-20$ & $57-367$ & 368 & 41849.17 & 9.51 \\
\hline Apu & Wnt2 & $1-33$ & $55-360$ & 378 & 42313.01 & 9.48 \\
\hline Apu & Wnt4 & $6-23$ & $50-355$ & 355 & 40016.32 & 9.42 \\
\hline Apu & Wnt5 & $12-33$ & $59-369$ & 369 & 41764.01 & 9.17 \\
\hline Apu & Wnt6 & $6-27$ & $\begin{array}{l}43- \\
154 / 151- \\
305\end{array}$ & 306 & 34473.72 & 8.43 \\
\hline Apu & WntA & $1-22$ & $60-360$ & 360 & 40776.92 & 9.37 \\
\hline Apu & WntA & & $1-153$ & 153 & 17497.82 & 9.58 \\
\hline Apu & Wnt7 & $1-47$ & $61-371$ & 371 & 42050.7 & 9.79 \\
\hline Apu & Wnt8 & $1-25$ & $58-353$ & 355 & 40367.57 & 9.64 \\
\hline Apu & Wnt9 & $1-23$ & $78-383$ & 383 & 44045.55 & 9.58 \\
\hline Apu & Wnt10 & & $83-385$ & 385 & 44009.43 & 9.39 \\
\hline Apu & Wnt11 & $1-25$ & $50-355$ & 355 & 39541.01 & 9.61 \\
\hline Apu & Wnt16 & & $28-335$ & 335 & 37902.6 & 9.33 \\
\hline
\end{tabular}


Five conserved Motifs were identified in Wnt proteins and designated as Motif 1 to 5 . In the bay scallops, most Wnt proteins (Wnt4, Wnt5, WntA, Wnt7, Wnt16, Wnt11, Wnt10, Wnt8) possessed all motifs (Fig. 1). However, Motif 5 was absent in Wnt2, Motif 4 was absent in Wnt1, Motif 1, 3 and 5 were absent in Wnt6, and Motif 2 was absent in Wnt9. Similarly, in Peruvian scallop, most Wnt proteins have all motifs, but Motif 1, 3 and 5 were absent in WntA, and Motif 2 was absent in Wnt9. A highly conserved domain was found near the $\mathrm{C}$-terminus while a structurally non-uniform $\mathrm{N}$-segment region was found in both the bay scallops and the Peruvian scallop (Fig. 2).

\section{Phylogenetic analyses of Wnt proteins}

A phylogenetic tree including Wnt proteins from 17 species was constructed using the NJ method (Fig. 3). All Wnt proteins can be grouped into 13 subfamilies, including Wnt11, Wnt16 and WntA. As can be seen from the figure, Wnt3 is only found in cnidaria and deuterostomes but absent in molluscs, indicating that there might be an independent deletion of Wnt3 gene in molluscs. As expected, Wnt genes in Peruvian scallops, bay scallops, and Japanese scallop are always grouped together into one branch, which is close to the branch containing oyster and mussels, but away from Cnidaria.

\section{Effects of temperature stress on expression of Wnt genes in Bohai Red scallops}

Three patterns were seen in the expression of scallop Wnt genes in response to different temperature stresses (Fig. 4). The first pattern was seen in Wnt genes such as Wnt1, Wnt6, Wnt7, Wnt11 and WntA, whose expressions were largely concordant in response to high and low temperature, with highest expression at 6-8h. The second pattern of response involves four Wnt genes, Wnt4, Wnt9, Wnt5 and Wnt2, which responded more rapidly to low temperature, with the highest expression at 6-8h, but slower to high temperature, with highest expression at 10-24h. The third pattern of response involved three Wnt genes, Wnt10, Wnt16 and Wnt8, which responded rapidly to high-temperature stress, with highest expression at 2-4h, and responded slowly to low-temperature stress, with highest expression at 8-24h.

\section{Discussion}

It has been more than 30 years since the discovery of Wnt genes [27]. Since then, Wnt genes have been found in various species. The origin of the Wnt gene family seems very ancient and diverse. Genomewide studies have suggested that 13 Wnt subfamilies may have existed in a common ancestor of cnidarians and bilaterian symmetrical animals. On the basis of the positional relationship of the distribution of Wnt genes across the genome, it was found that Wnt genes show some degree of linkage distribution across the genome and form a gene cluster with collinearity. In the common ancestor of cnidarian and bilaterally symmetrical animals, there may be two Wnt gene clusters with collinearity. One gene cluster is formed by the linkage distribution of Wnt9, Wnt1, Wnt6 and Wnt10, and the other gene cluster is composed of Wnt5 and Wnt7 [28-29]. 
Wnt gene family is well conserved in metazoa, and previous studies have shown that the Wnt genes in ancient metazoan may have 13 members. In this study, 12 Wnt genes were identified in two subspecies of Bay scallop and 13 were found in Peruvian scallop. Similarly, in a previous report, 12 and 11 Wnt genes were found in the Chinese scallop, Chlamys farreri and Japanese scallop, Patinopecten yessoensis, respectively, indicating that the number of Wnt genes in bivalves is basically conservative in evolution. Previous studies suggested that Wnt8 is lost in all mollusks and Wnt3 is present in cnidarian and bilaterian. However, in our study, Wnt8 gene can be identified in all three bivalves, which is similar to the result of another report [8]. It is possible that the loss of Wnt8 and presence of Wnt3 gene in bivalves were caused by certain events specific to bivalve. The fact that $25 \mathrm{Wnt}$ genes were identified in zebrafish whose genome is $1679 \mathrm{Mb}$ while only $11-13$ Wnt genes were found in bivalves whose genomes are around are $887 \mathrm{Mb}$. The genome size and the Wnt gene numbers of zebrafish is about twice than bay scallop. Therefore, we speculate that the expansion of gene family may be caused by genome-wide replication events. Wnt genes in Peruvian scallops, bay scallops, and Japanese scallop are always grouped together into one branch, which is close to the branch containing oyster and mussels, but away from Cnidaria.

Shellfish can produce harmful oxidative free radicals in normal physiological metabolism, but the antioxidant system tends to keep the free radicals at a normal level to maintain normal metabolic activities in animals. However, when organisms are stressed by environmental factors, excessive reactive oxygen species and oxygen free radicals will be produced, which may affect the balance of active oxygen metabolism in organisms. In this study, a large number of free radicals caused by extended stress may lead to oxidative damages such as apoptosis and inflammation in shellfish [30]. Previous studies have suggested Wnt gene family may play important roles in apoptosis inhibition and immune regulation, which may be beneficial to animals in dealing with apoptosis and inflammatory responses caused by stress [28]. In our study, in response to different temperature stress conditions, Wnt gene expression of scallop mainly showed three different response patterns. The relatively stable expression of the Wnt genes exhibiting the first response pattern (including Wnt1, Wnt6, Wnt7, Wnt11 and WntA) that were largely constant in response to high and low temperature may be related to the maintenance of basic homeostasis. The other Wnt genes seem to be either more sensitive to high temperature stress (such as Wnt4, Wnt9, Wnt5, and Wnt2 that exhibit second response pattern) or more sensitive to low temperature (such as Wnt8, Wnt 10 and Wnt 16 that exhibit third response pattern), suggesting that these genes may function more in organismal protection against high temperature or low temperature.

Unlike vertebrates, invertebrates lack adaptive immune system and rely solely on the innate immune system to resist the infection of pathogens. Therefore, innate immunity also represents the first, and sometimes perhaps the most important line of defense for invertebrates against external stimuli. Studies have shown that the expression of Wnt gene in infected Litopenaeus vannamei tissues is regulated at different levels, indicating that Wnt gene plays an important role in the innate immunity of Penaeus vannamei. In our study, Wnt gene expression in scallop tissues showed some differences under high and low temperature stress. We speculate that Wnt gene may also play an important role in the innate 
immunity of scallops. Therefore, further studies on roles of Wnt genes in immune of scallops are warranted and the results of this study will eventually benefit Bohai Red cultivation.

\section{Conclusions}

In this study, 12 and 13 Wnt genes were identified in the bay scallops and Peruvian scallop, respectively. Their gene characteristics and phylogenetic relationship were analyzed, which may provide new insights into the evolution of this gene family. We also showed that Wnt genes respond differentially to low and high temperature stress in Bohai Red scallop. Our results will lead to a better understanding of Wnt function and evolution in molluscs and eventually benefit Bohai Red scallop culture.

\section{Abbreviations}

KD: Kilo Dalton; NJ: Neighbor-joining

\section{Declarations}

\section{Ethics approval and consent to participate}

Not applicable.

\section{Consent for publication}

The authors consent to the above manuscript being published in BMC Genomics.

\section{Availability of data and material}

The data that support the research of this study are available from https://doi.org/10.5061/dryad.hdr7sqvdr. and some raw data was obtained from NCBI by BioSample accessions: SAMN08022140. Our material were obtained from the hatchery of Yantai SpringSea AquaSeed Co., Ltd. located at Laizhou, Shandong Province.

\section{Competing interests}

The authors declare that they have no competing interests.

\section{Funding}

This research was supported by National Natural Science Foundation of China (3197210450), Scientific and Technological Project of Yantai, Shandong Province (2019LJRC141) and Key Deployment Projects of Center for Ocean Mega-Science, Chinese Academy of Sciences (ZR2017QD001).

\section{Authors' contributions}


Caihui Wang and Min Chen collected all Wnt sequence from database. Caihui Wang did the comparative analyses of Wnt genes. Junhao Ning and Xia lu performed phylogenetic calculations. Bo Liu and Jinsheng Zhang designed the study and analyzed data. Chunde Wang wrote the manuscript. All authors commented on the manuscript and agreed to its final version.

\section{Acknowledgments}

We are grateful to all the laboratory members and anonymous reviewers for their technical advice and helpful discussions.

\section{References}

1. Amerongen, R.V. Alternative Wnt pathways and receptors. Cold Spring Harb Perspect Biol, 2012, 4:a007914

2. Freese JL, Pino D, Pleasure SJ. Wnt signaling in development and disease. Neurobiology of Disease, 2010, 38:148-53

3. Woll PS., Morris JK., Painschab MS., Marcus RK., Kohn AD., Biechele TL., Moon RT., Kaufman DS. Wnt signaling promotes hematoendothelial cell development from human embryonic stem cells. Blood, 2008, 111(1):122-31

4. Lengfeld, T., Watanabe, H., Simakov, O., Lindgens, D., Gee L., Law L., Schmidt HA., Ozbek S., Bode H., Holstein TW. Multiple Wnts are involved in Hydra organizer formation and regeneration. Dev. Biol. 2009, 330: 186-199.

5. Karner C, Wharton KA, Carroll TJ. Apical-basal polarity, Wnt signaling and vertebrate organogenesis. Seminars in cell \& developmental biology, 2006, 17(2): 214-22

6. Kusserow A, Pang K, Sturm C, Hrouda M, Lentfer J, Schmidt HA, Technau U, Arndt VH, Hobmayer B, Martindale MQ, Holstein W. Unexpected complexity of the Wnt gene family in a sea anemone. Nature, 2005, 433(7022):156-60

7. Sullivan JC, Ryan JF, Mullikin JC, et al. Conserved and novel Wnt clusters in the basal eumetazoan Nematostella vectensis. Development genes and evolution, 2007, 217(3):235-239

8. Bai Y, Nie H, Wang Z,Y an X. Genome-wide identification and transcriptome-based expression profiling of Wnt gene family in Ruditapes philippinarum. Comparative Biochemistry and PhysiologyPart D: Genomics and Proteomics, 2020, 35:100709

9. Genética D, Morfológica Y, Dos E, et al. Genetic and morpho-logical differentiation between two pectinid populations of Argopecten purpuratus from the northern Chilean coast. Estu-dios Oceanologicos. 2001, 1:51-60.

10. Estabrooks SL. The possible role of telomeres in the short life span of the bay scallop, Argopecten irradians irradians (Lamarck 1819). Shellfish Res 2007, 26(2):307-13.

11. Blake, N. J. \& Shumway, S. E. Chapter 17 Bay scallop and calico scallop fisheries, culture and enhancement in eastern North America. Developments in Aquaculture \& Fisheries Science. 2006, 


\section{5:945-964}

12. Dall WH. The mollusca and branchiopoda. Report of dredging operation, Albatros 1891. Bulletin Mollusca Comparative Zoology 1909, 37:147-294.

13. Wang C, Liu B, Li J, Liu S, Li J, Hu L, Fan X, Du H, Fang H. Introduction of the Peruvian scallop and its hybridization with the bay scallop in China. Aquaculture, 2010, 310 (3): 380-387

14. Wang Y, Guo X. Chromosomal rearrangement in pectinidae revealed by rRNA loci and implications for bivalve evolution. Biol Bull, 2004, 207: 247-56.

15. Xu D, Wang C, Liu B, Chen M, Zhao Y, Ma B, Liu G, Zhao X, Zhang J. Selection of a new scallop strain, QN-2, from the backcross of Peruvian scallop $\times$ bay scallop F1 hybrids with bay scallops. Aquaculture Research, 2019, 50(12): 3692-3699

16. Wang C, Liu B, Liu X, Ma B, Zhao Y, Zhao X, Liu F, Liu G. Selection of a new scallop strain, the Bohai Red, from the hybrid between the bay scallop and the Peruvian scallop. Aquaculture, 2017, 479(5):250-255

17. Chen M, Liu B, Ma B, Liu G, Cao W, Liu X, Yan X, Yang B, Wang C. Selection of a carotenoid-rich scallop strain, QN Orange, from the inter-specific hybrids between the bay scallop and the Peruvian scallop. Aquaculture, 2020, 528:735513

18. Scott C, Mary R. Emmett D, James P, Francis C, Chad A, Heather M, Jacqueline M, Anne B, Nancy K, Jeffrey P, Nancy N, William J, Lynne D. Climate Change Impacts on Marine Ecosystems. Annual Review of Marine Science, 2012, 4:11-37

19. Heuer RM, Grosell M. Physiological impacts of elevated carbon dioxide and ocean acidification on fish. American journal of physiology. Regulatory, Integrative and Comparative Physiology, 2014, 307 (9): R1061-84

20. Abele D., Puntarulo S. Formation of reactive species and induction of antioxidant defence systems in polar and temperate marine invertebrates and fish. Comparative Biochemistry and Physiology. Part A, Mol. Integr. Physiol. 2004, 138: 405-415

21. Bethanie CA, Noomi A, Britt W, Malin R, Fredrik J, Albin G, Kristina S, Michael A, Joachim S. Warmer water temperature results in oxidative damage in an Antarctic fish, the bald notothen. Journal of Experimental Marine Biology and Ecology, 2015,468:130-137

22. Li C, Liu X, Liu B, Ma B, Liu F, Liu G, Shi Q, Wang C. Draft genome of the Peruvian scallop Argopecten purpuratus. GigaScience, 2018, 7 (4): 1-6

23. Liu X, Li C, Chen M, Liu B, Yan X, Ning J, Ma B, Liu G, Zhong Z, Jia Y, Shi Q, Wang C. Draft genomes of two Atlantic bay scallop subspecies Argopecten irradians irradians and A. i. concentricus. Scientific Data, 2020, 7 (1): 99

24. Chen $\mathrm{C}$, Chen H, Zhang Y, Thomas HR, Frank MH, He Y, Xia R. TBtools: An Integrative Toolkit Developed for Interactive Analyses of Big Biological Data. Molecular Plant, 2020, 13 (8):1194-1202

25. Kumar S, Stecher G, Tamura K, MEGA7: Molecular Evolutionary Genetics Analysis Version 7.0 for Bigger Datasets. Mol Biol Evol, 2016, 33: 1870-4 
26. Liu S, Chen X, Lian S, Dai X, Hua N, Zhang F, Zhang L, Bao Z, Wang S. Genome-wide identification and expression profiling of the Wnt gene family in three bivalve molluscs. Comparative Biochemistry and Physiology -Part D, 2019, 2:299-307

27. Nusse $R$, Varmus HE. Many tumors induced by the mouse mammary tumor virus contain a provirus integrated in the same region of the host genome. Cell. 1982, 31 (1): 99-109

28. Garriock RJ, Warkman AS, Meadows SM, et al. Census of vertebrate Wnt genes: isolation and developmental expression of Xenopus Wnt2, Wnt3, Wnt9a, Wnt9b, Wnt10a, and Wnt16.

Developmental dynamics: an official publication of the American Association of Anatomists, 2007, 236 (5) :1249-1258

29. Bolognesi R., Beermann A., Farzana L., et al. Tribolium Wnts: evidence for a larger repertoire in insects with overlapping expression patterns that suggest multiple Redundant functions in embryo genesis. Development genes and evolution, 2008, 218 (3-4):193-202.

30. Carney AB, Bresolin SK, Jönsson E et al. Oxidative stress and biomarker responses in the Atlantic halibut after long term exposure to elevated $\mathrm{CO}$ and a range of temperatures. Comp Biochem Physiol B Biochem Mol Biol, 2019, 238: 110321

\section{Figures}
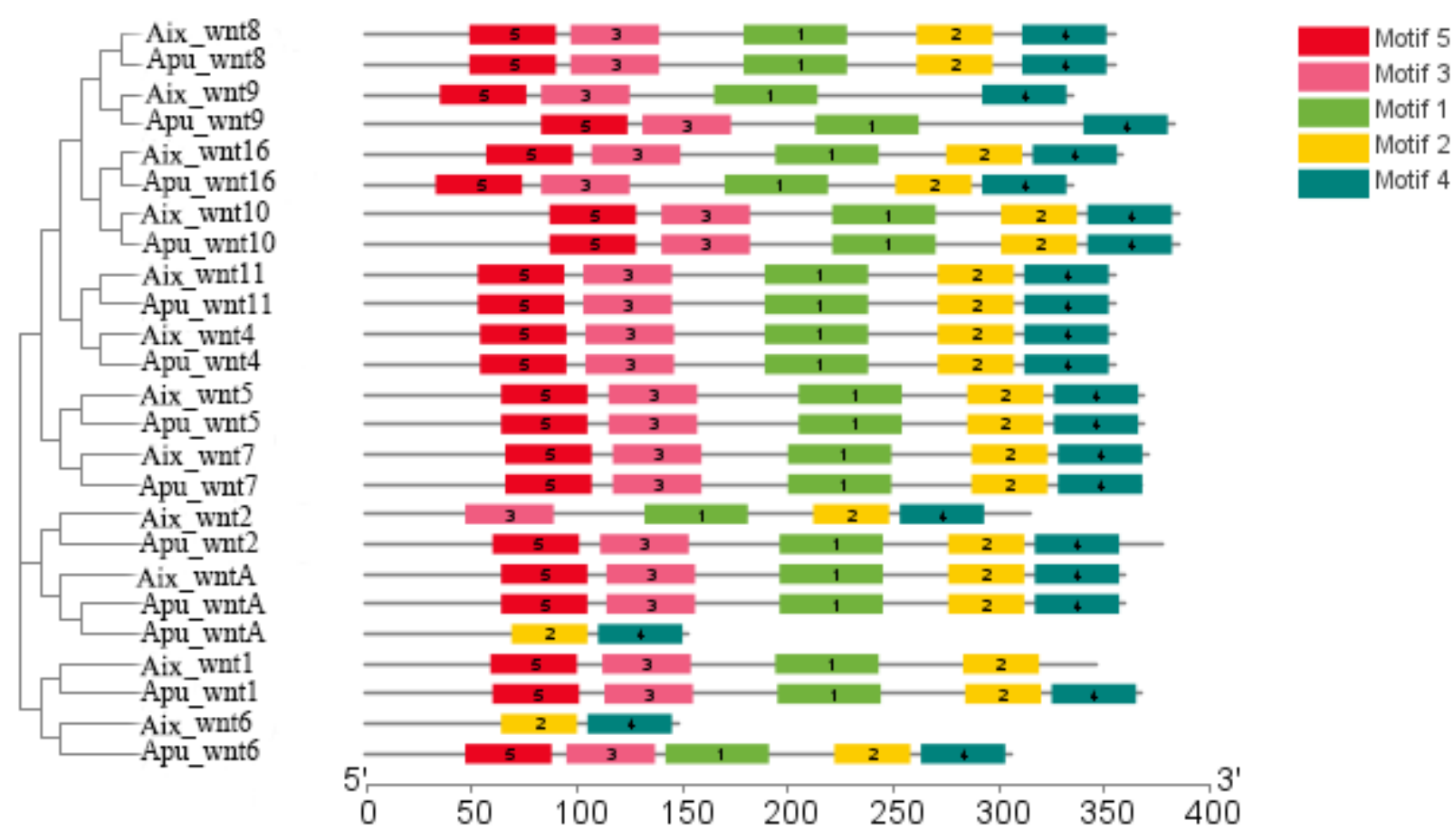

Figure 1

Motifs in Wnt proteins in the bay scallops and Peruvian scallop. Different colors represent different motifs. 


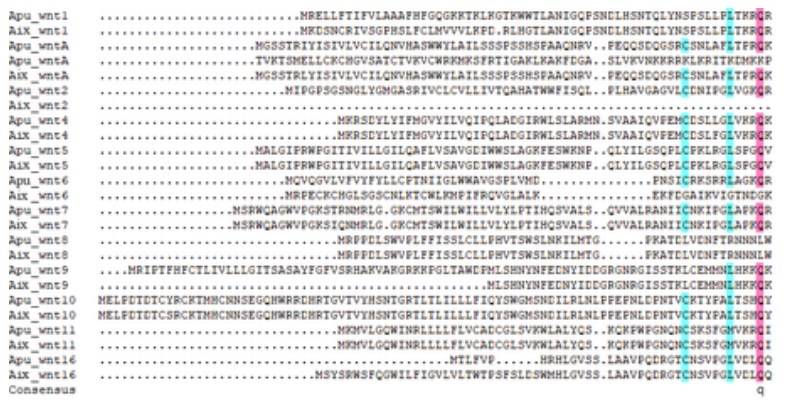

\footnotetext{
63
62
62
67
67
67
63
8
57
57
67
67
50
50
69
69
52
52
56
38
90
90
56
56
36
60
}

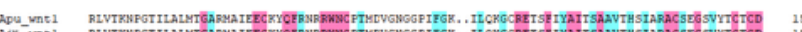
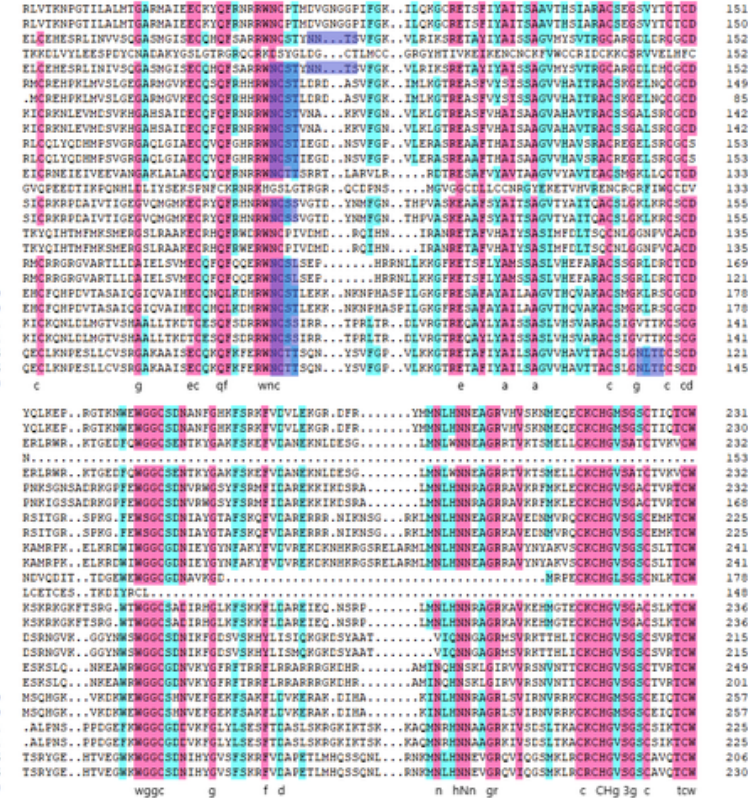

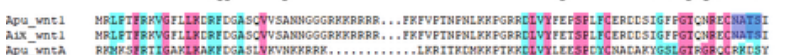

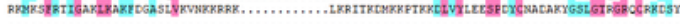

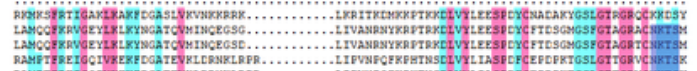

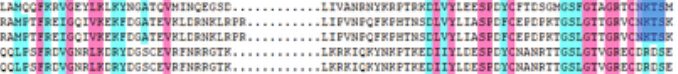

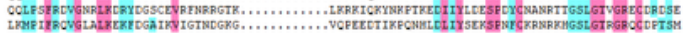

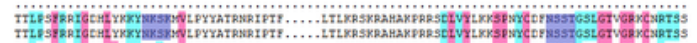

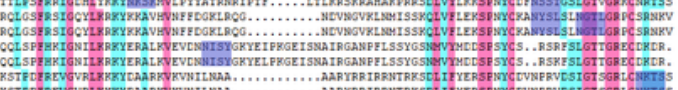

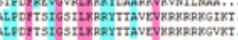

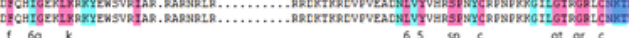
309

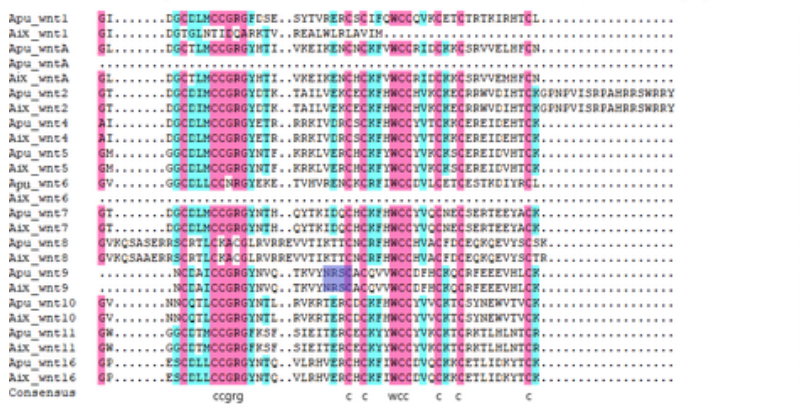

Figure 2

Amino acid sequence alignment of Wnt genes. Letters in purple show the predicted N-glycosylation sites. Letters in pink and blue indicate the most shared amino acids and the conserved amino acid groups, respectively. 


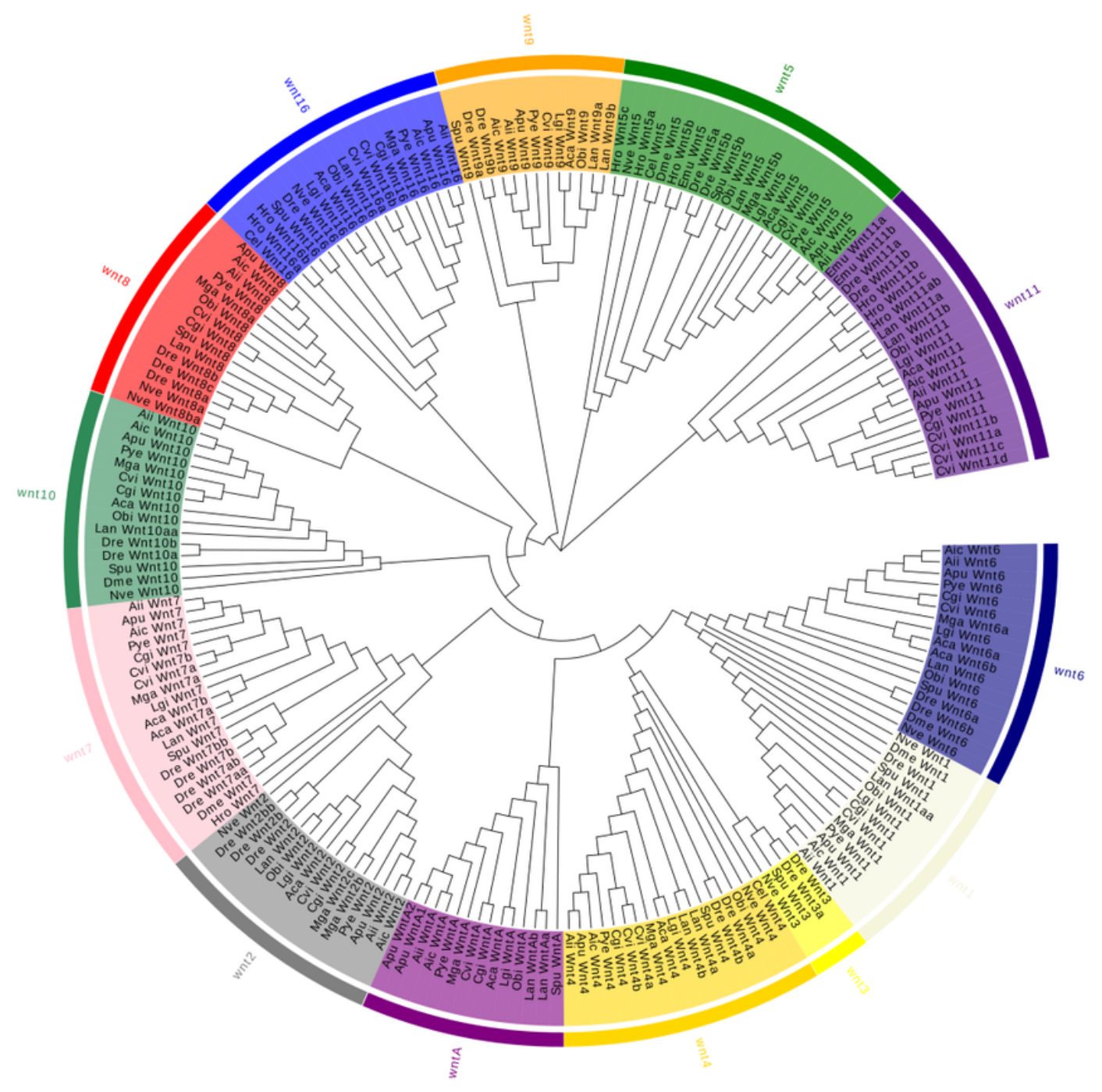

Figure 3

Phylogenetic analyses of the Wnt genes in 17 species using NJ method. Different colors represent different subfamilies, and a total of 13 subfamilies are included here. The abbreviations of the species names are listed in the Appendix.
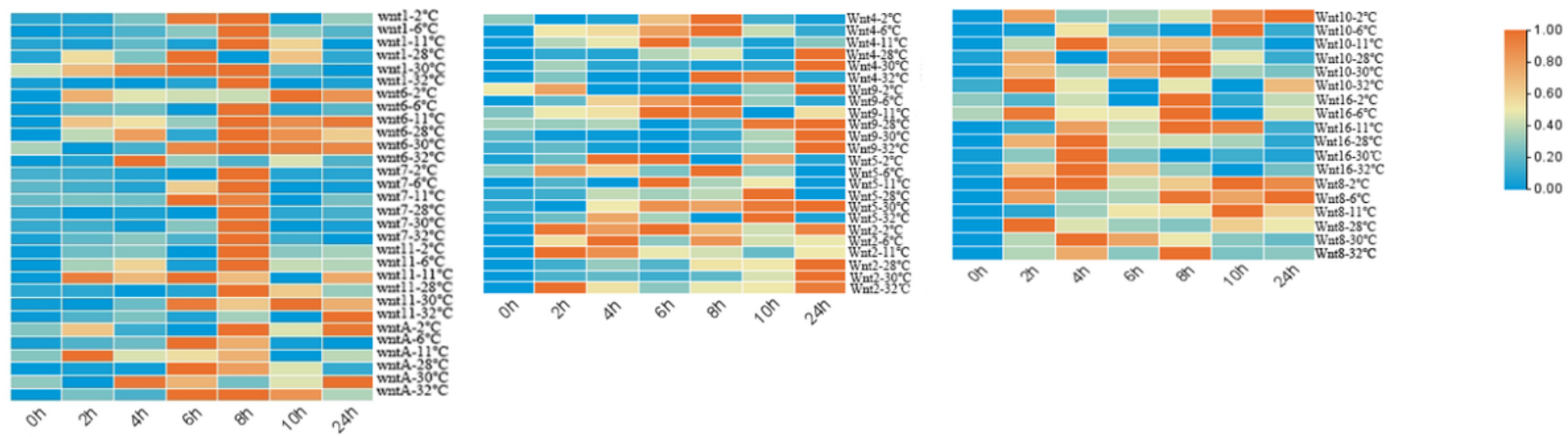
Figure 4

Expression of 12 Wnt genes in response to different temperature stresses. a. Wnt genes that were largely concordant in response to high and low temperature; $b$. Wnt genes that responded rapidly to low temperature but slowly to high temperature; c. Wnt genes that responded rapidly to high temperature but slowly to low temperature.

\section{Supplementary Files}

This is a list of supplementary files associated with this preprint. Click to download.

- Additionalfile1.docx

- Additionalfile2.docx

- Additionalfile3.docx 